\title{
Heat waves across Europe by the end of the 21st century: multiregional climate simulations
}

\author{
Brigitte Koffi ${ }^{1,3, *}$, Ernest Koffi ${ }^{2,3}$ \\ ${ }^{1}$ WSL, Swiss Federal Institute, PO Box 96, 1015 Lausanne, Switzerland \\ ${ }^{2}$ Institute of Applied Physics, University of Bern, 3012 Bern, Switzerland \\ ${ }^{3}$ Present address: Laboratoire des Sciences du Climat et de l'Environnement, Gif-sur-Yvette, France
}

\begin{abstract}
We investigated changes in the frequency, duration and intensity of heat wave (HW) events between the 20th and 21st centuries, as simulated across Europe by different regional climate models (RCMs). Based on local climate and on calendar day thresholds, the HW indices studied allow a consistent analysis across Europe and throughout the year. Simulations for 2 emission scenarios of greenhouse gases and for 4 model chains, consisting of 3 RCMs, driven by 2 global climate models (GCMs), were considered. Over the 1961-1990 period, the models reproduce fairly well the spatial distribution of fixed exceedance thresholds of the daily maximum temperature $\left(t_{\max }\right)$, although not the magnitude. On the other hand, they are qualitatively and quantitatively effective at reproducing the observed behaviour of the HW indices. Changes in $t_{\max }$ and in the HW indices were then studied. Because of changes in both the mean and in the variability of $t_{\max }$, the heat waves simulated for the future (2071-2100) across Europe are more frequent, more severe and they last longer. Their intensity and frequency increase by at least a factor of 3 , with highly differing patterns, depending on season and location. Thus, the increase in heat wave days observed across large parts of Europe during the last $30 \mathrm{yr}$ is expected to continue (winter) or even accelerate (summer) to the end of this century. The boundary conditions are the main source of uncertainty, whereas differences between RCMs driven by the same GCM are small.
\end{abstract}

KEY WORDS: Heat wave indices $\cdot$ Climate change $\cdot$ Regional climate models $\cdot$ Europe Resale or republication not permitted without written consent of the publisher

\section{INTRODUCTION}

The major heat wave that occurred across much of Europe in the first 2 wk of August 2003 (e.g. Schär et al. 2004) led to thousands of excess deaths in France, Italy, Spain and Switzerland (e.g. WHO 2003, Kovats et al. 2004, Stedman 2004, Grize et al. 2005). It also highlighted the environmental (e.g. hydrology, wildlife and ecosystems) and socio-economic (e.g. agriculture and cooling energy supply) problems that can arise if such events increase in frequency, intensity and persistence in the future. According to IPCC (2001) and studies performed at the global scale (e.g. Frich et al. 2002) or for Europe (e.g. Brabson \& Palutikof 2002, Domonkos et al. 2003), an increased incidence of hot spells in summer has been observed in the latter half of the 20th century.
Modelling studies, most of which are based on general circulation model (GCM) simulations, also show that an increase in the frequency of heat waves during the 21st century is highly likely (e.g. Huth et al. 2000, Kharin \& Zwiers 2000, Meehl et al. 2000). However, the 2001 report of the IPCC also cautioned as to the lack of adequate data and analyses that would provide a measure of confidence for these conclusions, and recognised the necessity to improve model projections, both in terms of quality and of regional detail. More recently, highresolution modelling studies confirmed that heat waves are likely to increase with elevated greenhouse gas concentrations (e.g. Pal et al. 2004 for Europe; Diffenbaugh et al. 2005 for the USA). Whereas the positive influence on human health of an increase in the occurrence of milder winters has been largely investi- 
gated in the past (e.g. Gawith et al. 1999 and references therein), there is little mention in the literature of episodes with anomalously warm temperature events other than during the summer season. However, mild periods during winter that may be qualified as extremes in a statistical sense can also have adverse effects on the environment or the economy, e.g. floods, adverse financial conditions for the winter sports industry, and disruptions to crop growth and final yield (Jones et al. 1999, Subak et al. 2000, Beniston et al. 2003).

The present study assesses changes in the frequency, intensity and duration of hot days and heat wave events between the later 20th (1961-1990) and 21st (2071$2100)$ centuries, on the basis of the daily maximum temperature $\left(t_{\max }\right)$, as simulated by high resolution regional climate models (RCMs) within the framework of the PRUDENCE (Prediction of Regional scenarios and Uncertainties for Defining EuropeaN Climate change risks and Effects) project (Christensen et al. 2007). Responses to the SRES (Special Report on Emission Scenarios) A2 and B2 greenhouse gas scenarios (Nakićenović et al. 2000) were investigated. The method used, dynamical downscaling, consists of running a highresolution RCM (typically 20 to $50 \mathrm{~km}$ ) over a limited domain, using boundary conditions provided by a GCM simulation. It generally simulates relatively realistic structure and evolution of synoptic events, but at much finer spatial and temporal scales, allowing substantial improvements compared to the driving GCM (see, for instance, Jones et al. 2001, Bell et al. 2004). Investigations of extreme heat should therefore benefit from this project, as such events can be localised at scales which are poorly resolved by GCMs. In addition, the large set of simulations produced within PRUDENCE was aimed to assess uncertainties in prediction as a function of the model formulation, climate variability and radiative forcing (i.e. the emission scenario).

The first part (Section 2) of this paper consists of a brief description of the modelled data as well as of the observation time series used for their validation. Section 3 is devoted to the heat wave indices investigated. The occurrence of extreme temperature events across Europe for present-day (1961-1990) and future (20712100) climates are discussed in Sections 4 and 5, respectively. Section 6 gives the main conclusions and perspectives.

\section{DATA}

\subsection{Model data}

A large set of simulations has been produced within the PRUDENCE project by using a hierarchy of models consisting of 3 coupled Atmosphere-Ocean GCMs
(AOGCMs), 4 atmospheric GCMs and 8 nested RCMs, with grid meshes ranging from 50 to $20 \mathrm{~km}$. A detailed description of the experiments and models is in Christensen \& Christensen (2007) and Déqué et al. (2007), respectively. Only 2 SRES scenarios were considered: the A2 scenario assumes large (in comparison with most of the other SRES scenarios) and continuously increasing emissions of $\mathrm{CO}_{2}, \mathrm{CH}_{4}$ and $\mathrm{N}_{2} \mathrm{O}$, whereas the $\mathrm{B} 2$ scenario corresponds to a lower increase in $\mathrm{CO}_{2}$ and $\mathrm{CH}_{4}$, i.e. in the lower mid-range of the SRES scenarios (IPCC 2001).

Uncertainties due to sampling, radiative forcing (A2 versus B2), boundary conditions (driving GCM) and to the RCM were assessed for 2071-2100 temperature and precipitation during the PRUDENCE project (Déqué 2003, Déqué et al. 2007) from a total of 20 PRUDENCE experiments. Results showed that the radiation forcing (emission scenario) was the most important source of uncertainty for temperature, followed by the boundary layers, for both the winter and summer seasons. On the basis of these preliminary analyses, simulations from 4 GCM-RCM model chains, consisting of 4 RCMs and 2 driving GCMs, and 5 prediction experiments (4 A2 and $1 \mathrm{~B} 2$ scenario runs) are considered in this study. They have been selected so as to well cover the range of uncertainties obtained in the 2071-2100 daily temperature data, with B2.3 showing the least temperature increase and A2.4 providing the highest increase.

The first set of A2 scenario experiments (Table 1) consisted of the simulations by the Danish HIRHAM4 (Christensen et al. 1998), the Swiss CHRM (Lüthi et al. 1996, Vidale et al. 2003) and the Swedish RCAO (Döscher et al. 2002, Räisänen et al. 2003, 2004) highresolution RCMs, driven at their lateral boundaries by the HadAM3H GCM (Buonomo et al. 2007), which is a high-resolution version of the atmospheric component of the HadCM3 AOGCM (Gordon et al. 2000). In the following, the corresponding simulations will be denoted the A2.1, A2.2 and A2.3 experiments, respectively. Another A2 scenario run (hereafter, A2.4 experiment) from the RCAO regional model but driven by the ECHAM4/OPYC3 model (Roeckner et al.1999) was also considered, in order to study the effects of the driving GCM. The ECHAM4/OPYC3 model is a coupled AOGCM forced directly with SRES emission scenarios. The time-slice experiments (1961-1990 and 2071-2100) from the HadAM3H model used surface boundary conditions from HadCM3 simulations. In all PRUDENCE simulations, sea surface temperatures (SSTs) used are interpolations from coupled AOGCM SSTs (except for the Baltic in RCAO). Finally, predictions based on the SRES B2 emission scenario, as simulated by the HadAM3H/RCAO model chain (hereafter, B2.3 experiment), were also investigated in order to assess 
Table 1. Control run (1961-1990) and future scenario (2071-2100) experiments in the present study. DMI: Danish Meteorological Institute; ETHZ: Swiss Federal Institute of Technology; SMHI: Swedish Meteorological Institute; RCM: regional climate model; GCM: global climate model

\begin{tabular}{|c|c|c|c|c|c|}
\hline Institute & $\begin{array}{l}\text { Model } \\
\text { chain }\end{array}$ & $\mathrm{RCM}$ & $\begin{array}{l}\text { Driving } \\
\text { GCM }\end{array}$ & Expt & Acronym \\
\hline DMI & 1 & HIRHAM4 & HadAM3H & $\begin{array}{c}\text { Control } \\
\text { Scenario A2 }\end{array}$ & $\begin{array}{l}\text { CR.1 } \\
\text { A2.1 }\end{array}$ \\
\hline ETHZ & 2 & CHRM & HadAM3H & $\begin{array}{c}\text { Control } \\
\text { Scenario A2 }\end{array}$ & $\begin{array}{l}\text { CR. } 2 \\
\text { A2. } 2\end{array}$ \\
\hline \multirow[t]{2}{*}{ SMHI } & 3 & $\mathrm{RCAO}$ & HadAM3H & $\begin{array}{c}\text { Control } \\
\text { Scenario A2 } \\
\text { Scenario B2 }\end{array}$ & $\begin{array}{l}\text { CR.3 } \\
\text { A2.3 } \\
\text { B2.3 }\end{array}$ \\
\hline & 4 & RCAO & ECHAM4/OPYC & $\begin{array}{c}\text { Control } \\
\text { Scenario A2 }\end{array}$ & $\begin{array}{l}\text { CR. } 4 \\
\text { A2.4 }\end{array}$ \\
\hline
\end{tabular}

the uncertainty associated with the future atmospheric concentrations of greenhouse gases and aerosols, i.e. with radiative forcing.

The 30 yr annual global mean warming from 19611990 to 2071-2100 for the A2 (B2) forcing scenario is $3.2^{\circ} \mathrm{C}\left(2.3^{\circ} \mathrm{C}\right)$ in HadAM3H and $3.4^{\circ} \mathrm{C}\left(2.6^{\circ} \mathrm{C}\right)$ in ECHAM4/OPYC3 (Räisänen et al. 2004). These values are in the mid-range of the uncertainty interval reported by Cubasch et al. (2001). Together with the corresponding control runs from the 4 model chains (CR.1, CR.2, CR.3, CR.4 experiments), a total of 9 experiments (Table 1) were investigated. Each of the corresponding $30 \mathrm{yr}$ datasets consisted of 12 mo with 30 d (i.e. 10800 daily data) for each of the $11440(110 \times$ $104), 4875(65 \times 75)$ and $7740(90 \times 86)$ grid points of HIRHAM4, CHRM and RCAO domains across Europe, respectively.

\subsection{Observation data}

Quantitative inter-comparison and evaluation work has been done by the partners of the PRUDENCE project, who are responsible for validation aspects (Jacob et al. 2007). Therefore, in a first step, we only made a qualitative assessment of the GCM-RCM model chains' ability to reproduce 1961-1990 temperatures by using the NCEP-NCAR reanalysis (www.cdc.noaa.gov/ cdc/reanalysis/; Kalnay et al. 1996). Statistical parameters of the simulated probability density function (PDF) of $t_{\max }$ were mapped and compared to these reanalyses at seasonal and annual time scales (Section 4.1) to make sure that we had been provided with realistic model outputs. In a second step (Section 4.2), a more detailed station analysis was provided in order to statistically assess the ability of the different models in reproducing selected indices of a heat wave. The daily time series observation dataset assembled within the framework of the European Climate Assessment and dataset project (ECA) for 199 stations across Europe (Klein Tank et al. 2002) was used. Attention was paid to select only those ECA stations with complete and reliable time series, i.e. without missing data or artificial breaks over the 1961-1990 period. The reliability of the time series was checked by examining the results of the 4 homogeneity tests (standard normal homogeneity, Von Neumann ratio, Buishand range and Pettitt test) performed by Wijngaard et al. (2003). A total of 13 stations was retained, so as to achieve the best possible north to south (Finland to Greece) and west to east (UK to Russia) spatial coverage across Europe (Fig. 1). None of the available 1961-1990 observation time series met the required selection criteria in the north-central part of Europe (Poland, Estonia, Lithuania, Latvia and Belarus). Nevertheless, the Voru station (Estonia), which shows a reliable but somewhat incomplete series of data, was selected to illustrate the patterns of heat wave changes in this region (Section 5.3.3). Despite the limited number of reliable observation series, the sample allows significant progress in the assessment of the capability of RCMs in reproducing the regional and seasonal temperature variability across the continent.

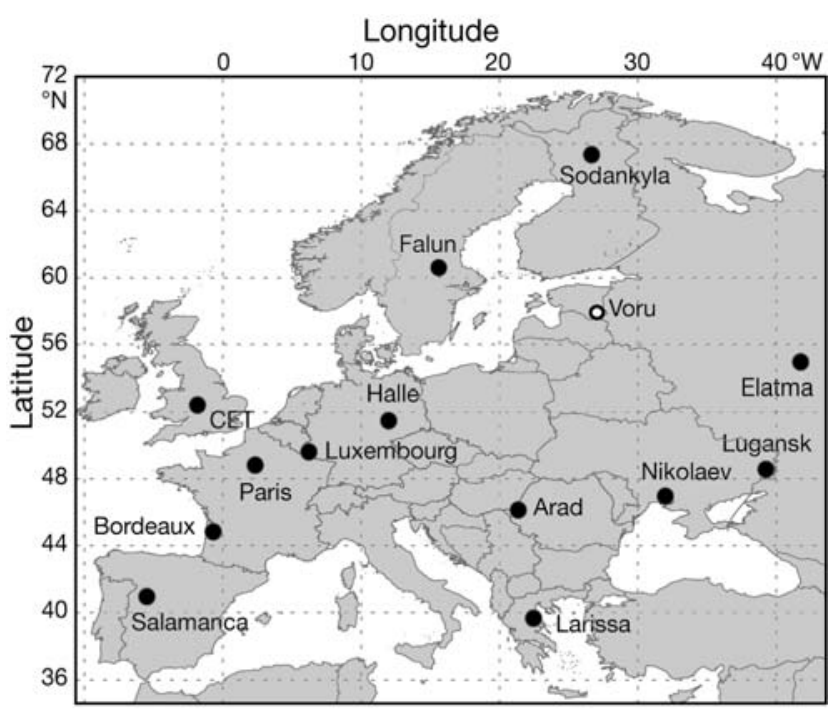

Fig. 1. The 13 stations (๑) selected across Europe for the validation of the simulated heat indicators, using European Climate Assessment (ECA) time-series observations. Voru (Estonia) station (O). CET: historical Centre England temperature data 


\section{METHODS}

To emphasise the character of the changes in the PDFs of $t_{\max }, 12$ summary statistical parameters of the PDFs (mean, maximum, minimum, standard deviation, 1st, 5th, 10th, 25th, 75th, 90th, 95th, 99th percentiles) were computed at each grid point and mapped across Europe. Several indices of heat waves were then investigated, based on calendar-day thresholds defined from the local climate.

\subsection{Temperature thresholds}

In a preliminary study, we analysed changes in the exceedance of absolute thresholds across Europe (Koffi 2003, Beniston et al. 2007). Results revealed that the future climate at a given location might be as warm as the climate observed 400 to $500 \mathrm{~km}$ south of that location in the second half of the 20th century. For instance, regions such as SW France or Hungary may experience, in a future climate, a frequency of days with temperatures $>30^{\circ} \mathrm{C}$ as high as that currently observed in the south of Spain or in Sicily. In addition, model results reveal an extension of the period within the year during which hot days may occur in the future. Such fixed thresholds have often been investigated in the past (e.g. Mearns et al. 1984, DeGaetano 1996, Plummer et al. 1999, Huth et al. 2000, Kysely 2002), since they are the most easily understood by a non-specialist audience and the easiest for the regional media and politicians to grasp. On the other hand, they are regionally dependent and so are less suitable for spatial comparisons of extremes over an area as large as the European continent. For instance, the exceedance of $30^{\circ} \mathrm{C}$, which is very common in Madrid, can be considered a rare event in Helsinki. Likewise, a threshold of $25^{\circ} \mathrm{C}$ will mainly sample summer temperatures in the northern part of Europe and spring and autumn temperatures in the south.

Therefore, in addition to the number of days with $t_{\max }>25^{\circ} \mathrm{C}$ and $30^{\circ} \mathrm{C}$ (EXC_25 and EXC_30 indices), heat wave indices were defined (Section 3.2) and studied using percentile thresholds. In that case, all the data were used, rather than just the tail. The thresholds change according to the local characteristics of the data, so that such an analysis can be done consistently over a large region, such as Europe. Since they are based on prevailing climatic conditions in a given location, they better account for the ability of people or ecosystems to cope with hot/cold extremes (Gawith et al. 1999, WMO 1999, Robinson 2001). Moreover, the results are less sensitive to the underlying distribution than are methods that use a specific distribution to fit all the data (Peterson et al. 2001). Following the IPCC
(2001) definition of an extreme weather event, i.e. 'as rare as or rarer than the 10th or 90th percentile', we considered the 90th percentile as the threshold value above which abnormally elevated temperatures occur.

\subsection{Heat wave indices}

Heat waves are difficult to define; no general meteorological definition exists (Giles \& Balafoutis 1990). They typically occur on synoptic scales and are often associated with the development of large stationary or quasi-stationary high pressure systems in the extratropics. They are often defined in terms of occurrence of extreme high surface air temperature values that persist for a period of several days (WMO 1999). The notion of what may locally constitute high air temperature is relative in terms of site and season. Using the 1961-1990 90th mean percentile, as previously done for the 'hot day' definition, would confine the events for most of Europe to the summer season, however stressful or damaging a less hot event at another season may be.

The heat wave (HW) events investigated in this study were therefore defined from $t_{\max }$ using calendar day thresholds, which are calculated over a $5(=\mathrm{n} 1)$ day window, centred on each calendar day of the $30 \mathrm{yr}$ $(=\mathrm{n} 2)$ climate period, i.e. from $150(\mathrm{n} 1 \times \mathrm{n} 2)$ daily values. This calculation method, recommended by the World Meteorological Organization-Commission for Climatology (WMO-CCL) and the Research Programme on Climate Variability and Predictability (CLIVAR) has been applied within the framework of the ECA European project to the definition of frequency (HWFI) and duration (HWDI) heat wave indices, respectively, based on the 90th percentiles and on the mean $+5^{\circ} \mathrm{C}$ calendar day thresholds (www.knmi.nl/ samenw/eca/descriptions/). However, unlike the ECA project, we used the same thresholds (calendar day 90th percentiles) for all the frequency, intensity and duration indices, since we consider that a threshold based on a fixed number of added degrees above the mean could objectively only be set according to the local climate, and especially to its variability. Frich et al. (2002) concluded that the HWDI has limited usefulness, especially in some warm, stable climates with such low variability that no heat wave can be identified from this index for past climates. Nevertheless, our criterion of heat wave duration, which is a key factor for the human ability to cope with heat events (e.g. Kalkstein \& Smoyer 1993, Basu \& Samet 2002) is also based on a minimum of 6 consecutive days above thresholds, thereby allowing further comparison with results of the ECA project for the present-day climate (Section 5.3.3). 
We used 4 heat wave indices in this study to document the occurrence of heat wave events in terms of frequency ( 2 indices), duration (1 index) and intensity (1 index), which are defined as follows:

- HW_F (heat wave frequency index, which corresponds to the above-mentioned HWFI): total number of days per (annual or seasonal) period, with a spell of at least 6 consecutive days that are above the 1961-1990 calendar day 90th percentiles (unit = days)

- N_HW (number of heat waves): number of heat waves per period with a spell of at least 6 consecutive days

- HW_D (heat wave duration index): maximum number of consecutive heat wave days (i.e. longest heat wave of at least 6 consecutive days) per period (unit $=$ days)

- HW_I (heat wave intensity index): highest value per period of the number of cumulated daily degrees above the threshold, as calculated for each heat wave of at least 6 consecutive days (unit = degree-days)

Both HW_F and N_HW frequency indices take into account all heat wave days in spells of at least $6 \mathrm{~d}$, whereas the HW_D duration and the HW_I intensity indices, which are representative of 1 specific event per period, represent the longest and the most intense heat wave, respectively. The HW_I index quantifies the number of degrees over the threshold as cumulated over the consecutive days of the heat wave. Although it is not calculated from the $24 \mathrm{~h}$ average, but from only the hottest hour of the day, it gives a useful indication of the heat accumulation over the warmest (annual or seasonal) spell, i.e. of its magnitude.
Fig. 2 illustrates the method as applied to $t_{\max }$ at Paris-Montsouris station $\left(48^{\circ} 49^{\prime} 24^{\prime \prime} \mathrm{N}, 2^{\circ} 20^{\prime} 12^{\prime \prime} \mathrm{E}\right)$ : a total of 17 heat waves was identified, only 5 of which occurred during the summer months (June, July and August). The highest heat wave frequency was obtained in 1990, with 4 heat waves (17 to 24 February, 15 to 21 March, 30 April to 7 May and 30 July to 4 August), consisting of a total of $29 \mathrm{~d}$. The well-known 1976 heat wave is conspicuous. It corresponds to the longest (16 d persistence) and most intense event over the 1961-1990 period (HW_I I $_{1976}=75$ degree-days, corresponding to a mean daily intensity of $4.7^{\circ} \mathrm{C}$ above thresholds). It was, however, less intense than the 12 consecutive days of the August 2003 record-breaking heat wave, which showed a mean daily threshold exceedance of $7.3^{\circ} \mathrm{C}$.

As expected, and as for other climate extreme indicators, the distributions (not shown) are far from Gaussian distributions, with the HW indices presenting the more complex statistical properties. Thus, because of their definition, they can only take the values 0 (no heat wave in a year) or $>5$. This prohibits the use of parametric statistical tests (e.g. Student $t$-test) to estimate the significance of the agreement between modelled and observed indices. Therefore, distributionfree tests were used in Section 4 to evaluate the ability of the models to reproduce the distribution function of the annual indices, in terms of median location (MannWhitney $U$-test) and cumulative frequency (Kolmogorov-Smirnov test). In addition, a Spearman correlation test was performed between the modelled and observed mean values of the 13 sites, in order to assess the ability of the models to reproduce the spatial patterns of the $30 \mathrm{yr}$ averaged indices.

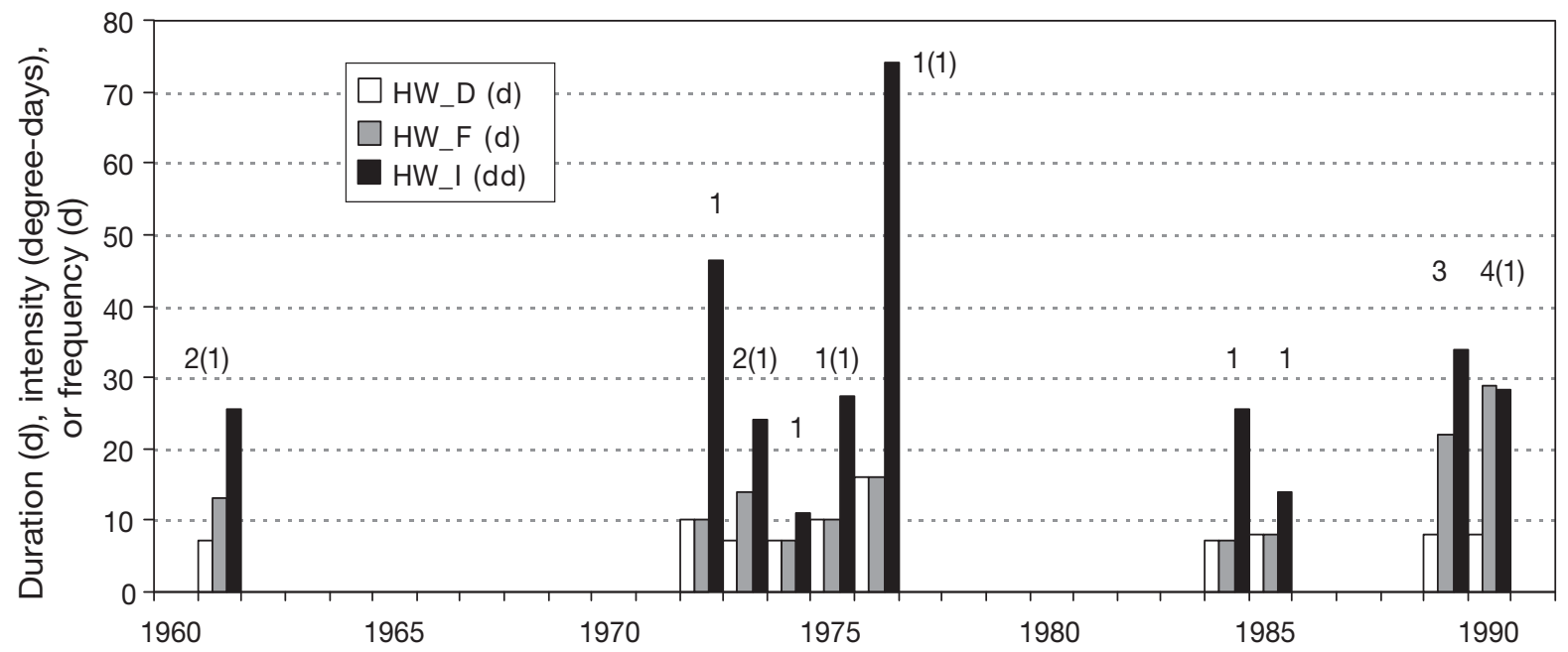

Fig. 2. The 1961-1990 heat wave duration (HW_D), intensity (HW_I) and frequency (HW_F) indices calculated from $t_{\text {max }}$ (ECA data set) at the Paris-Montsouris station (France) for 17 heat waves. Numbers at top of bars are annual (summer) number of heat waves, i.e. the N_HW index (see Section 3 for definitions) 


\section{PRESENT-DAY CLIMATE (1961-1990)}

\subsection{Probability density function of $t_{\max }$}

We made a preliminary study at the beginning of the project to check whether we had been provided with realistic 1961-1990 simulated temperatures: the statistical parameters of the simulated PDFs (see Section 3) from the 4 control runs were mapped and compared to NCEP-NCAR reanalysis. The results (not shown for the sake of brevity) demonstrated the ability of the different models in reproducing 1961-1990 average patterns of $t_{\text {max }}$ PDFs, both in terms of shape and central location. However, investigating space and time in more detail revealed that local discrepancies may occur. Thus, applying a Levene $F$-test showed statistically significant differences $(\alpha>5 \%)$ between observations and reanalyses for the variance, for the mean in many cases and for the 4 seasons. No systematic bias (under-/overestimation) occurred according to the model or the season.

Studies of the variability of 1961-1990 temperatures in PRUDENCE RCM control runs have also been performed by Lenderink et al. (2004) and Giorgi et al. (2004), but for the summer months only. Results showed a significant overestimation of the inter-annual variability of temperature for most areas in central Europe and across the Mediterranean regions. These preliminary results were recently completed and synthesized by Jacob et al. (2007). Using the University of East Anglia's Climate Research Unit (CRU) climatology (New et al. 1999), a model validation has been performed to assess the ability to simulate both the long-term (30 or $40 \mathrm{yr}$ ) mean climate and inter-annual variability. The analysis for near-surface air temperature and for winter and summer showed a warm bias with respect to the CRU data set in these extreme seasons and a tendency to cold biases in the transition seasons. In winter the typical spread (standard deviation) between the models is $1 \mathrm{~K}$. During summer there is generally better agreement between observed and simulated values of inter-annual variability, although there is a relatively clear signal that the modelled temperature variability is larger than suggested by observations. While there are clearly uncertainties, these are shown to be smaller than the average climate response. However, such discrepancies between RCM simulations and observations may induce significant over- or underestimations of the occurrence of temperature extremes (see for instance Moberg \& Jones 2004). Therefore, they demonstrate the necessity to carry out a statistical evaluation of the different models' abilities to reproduce, for the 1961-1990 climate, the indices of extreme temperature that are considered in the present study.

\subsection{Indices of warm extremes}

The calendar day thresholds and the annual values of the 6 indices of temperature extremes were first calculated over the 1961-1990 period for all grid points in RCM domains. In order to assess and quantify the ability of the 4 model chains to reproduce the studied indicators, a validation was performed for the grid points closest to the 13 selected stations (see Section 2.2 and Fig. 1).

The 1961-1990 average EXC_25 and EXC_30 annual indices, as well as the N_HW, HW_D, HW_F and HW_I heat wave indices, as computed from observation and daily simulation data are reported in Table 2 . The significance of the statistical tests described in Section 3 are reported below.

Results reveal that from 8 to 13 (depending on the model) of the 13 stations show a statistically significant difference $(\alpha<5 \%)$ between the modelled and observed medians of EXC_25 distributions. Results for the $30^{\circ} \mathrm{C}$ threshold range from 5 to 10 stations. Nevertheless, in both cases, high correlations $(\alpha<1 \%)$, for both Spearman and Pearson tests were obtained between the control runs and observations for the median (not shown) and mean values of the 13 sites. This demonstrates the ability of the different models to capture the patterns of the spatial distribution, i.e. the highly marked north to south gradient of the mean number of days above the 25 and $30^{\circ} \mathrm{C}$ thresholds.

A much higher correspondence was obtained between model and observations for the heat wave indices than for the fixed thresholds. A good agreement (Mann-Whitney test, $\alpha<5 \%$ ) was obtained for all the stations between the observed and simulated values of HW_F and HW_I indices, whereas such an agreement was also obtained for at least 12 of the 13 stations for the N_HW (number of heat wave) and the HW_D (duration) indices. Results of the KolmogorovSmirnov test $(\alpha<5 \%)$ also show the ability of the different models to reproduce, in most cases, the shape of the cumulative distributions of the 30 annual values.

The models reproduce the main spatial patterns of the mean occurrence of days above 25 and $30^{\circ} \mathrm{C}$ absolute thresholds across Europe, although significantly different values compared to observations were quite commonly obtained. On the other hand, the simulated heat wave indices show a very good agreement with observations $(\alpha<5 \%)$ in most cases. This can be explained by the use of thresholds based on a fraction $(10 \%)$ of the total number of days rather than on a given temperature value, which avoids discrepancies due to under- or overestimation of the temperature levels. It also logically leads to a quite homogenous spatial distribution of the occurrence of 
Table 2. Mean 1961-1990 annual values of the 6 indices of temperature extremes as calculated from observed (ECA) and simulated (see Table 1 for definition of the control runs) daily maximum temperature $\left(t_{\max }\right)$ series at the 13 selected stations. Significant agreements $(\alpha<5 \%)$ between simulations and observations for the median (Mann-Whitney test) and the cumulative frequency distribution (Kolmogorov-Smirnov test) are indicated in bold and underlined characters, respectively. Significant $(\alpha<1 \%)$ Spearman and Pearson correlation coefficients were obtained between the 13 pairs of simulated and observed EXC_25 and EXC_30 mean values

\begin{tabular}{|c|c|c|c|c|c|c|c|c|c|c|}
\hline$t_{\max }$ data & ECA & CR.1 & CR.2 & CR.3 & CR.4 & ECA & CR.1 & CR.2 & CR.3 & CR.4 \\
\hline & \multicolumn{5}{|c|}{$\longrightarrow$ EXC_25 (annual days) } & \multicolumn{5}{|c|}{- EXC 30 (annual days) - } \\
\hline Arad & 86 & 85 & 104 & 101 & 101 & 24 & 29 & 56 & 51 & 55 \\
\hline Bordeaux & 58 & 73 & 89 & 54 & 44 & 14 & $\overline{31}$ & 37 & 13.2 & 9 \\
\hline CET & 6.7 & 9 & 19 & $\overline{6}$ & 2 & 0.5 & 0.3 & 2 & $\overline{0.3}$ & $\mathbf{0}$ \\
\hline Elatma & 39 & 41 & 15 & $\overline{44}$ & 36 & 6 & $\overline{11}$ & 2 & $\overline{14.5}$ & $\overline{8}$ \\
\hline Falun & 17 & 7 & 0.2 & $\overline{1}$ & 0.3 & 1 & 1 & 0 & 0.03 & $\overline{0}$ \\
\hline Halle & 35 & $\underline{35}$ & $\underline{32}$ & $\underline{34}$ & 22 & 6 & $\underline{7}$ & $\underline{\mathbf{5}}$ & 6 & 3 \\
\hline Larissa & 143 & 153 & $\underline{145}$ & $\overline{122}$ & 131 & 82 & 103 & 93 & 63 & 77 \\
\hline Lugansk & 88 & 99 & $\overline{71}$ & $\underline{94}$ & 97 & 29 & 52 & $\underline{29}$ & 52 & 45 \\
\hline Luxembourg & 23 & 30 & 37 & $\overline{28}$ & 18 & 3 & $\underline{4}$ & $\overline{7}$ & $\underline{4}$ & $\underline{1}$ \\
\hline Nikolaev & 86 & 109 & 93 & $\underline{\overline{82}}$ & 72 & 26 & $\overline{65}$ & 45 & $\overline{33}$ & $\underline{21}$ \\
\hline Paris & 36 & 44 & 51 & $\underline{42}$ & 29 & 6 & $\underline{9}$ & 11 & 10 & $\underline{5}$ \\
\hline Salamanca & 91 & $\underline{85}$ & 106 & $\underline{82}$ & 97 & 34 & $\underline{32}$ & 55 & $\underline{32}$ & 42 \\
\hline \multirow[t]{2}{*}{ Sodankyla } & 6 & 0.5 & 0.03 & 0.7 & 0.2 & 0.3 & 0 & $\underline{\mathbf{0}}$ & $\underline{0}$ & $\underline{\mathbf{0}}$ \\
\hline & \multicolumn{5}{|c|}{ _ N_HW (annual counts) } & \multicolumn{5}{|c|}{ _ HW_F (annual days) } \\
\hline Arad & 0.73 & 0.67 & $\underline{0.83}$ & $\underline{0.90}$ & $\underline{0.87}$ & 5.3 & $\underline{5.8}$ & $\underline{6.2}$ & $\underline{6.9}$ & $\underline{6.0}$ \\
\hline Bordeaux & 0.53 & 0.63 & $\overline{0.87}$ & $\overline{0.63}$ & $\overline{0.83}$ & 4.3 & $\underline{4.5}$ & $\overline{6.5}$ & $\underline{4.4}$ & $\underline{6.1}$ \\
\hline CET & 0.80 & 0.73 & $\underline{0.77}$ & $\underline{0.97}$ & $\underline{0.83}$ & 6.0 & $\overline{5.6}$ & $\underline{6.0}$ & $\overline{7.3}$ & $\overline{5.8}$ \\
\hline Elatma & 0.83 & $\overline{1.03}$ & 1.20 & 1.20 & 0.77 & 6.4 & 8.9 & 9.6 & $\overline{10.4}$ & 6.6 \\
\hline Falun & 0.77 & $\underline{0.83}$ & $\underline{0.67}$ & $\underline{0.67}$ & $\underline{0.67}$ & 6.2 & $\underline{6.4}$ & $\underline{5.2}$ & $\underline{5.5}$ & $\underline{5.1}$ \\
\hline Halle & 0.73 & 0.73 & 0.87 & 0.87 & 0.83 & 5.6 & 5.4 & 6.6 & 6.6 & 6.4 \\
\hline Larissa & 0.66 & 0.70 & 0.73 & 0.77 & 0.57 & 5.0 & $\underline{5.2}$ & $\overline{5.5}$ & $\overline{5.9}$ & 3.9 \\
\hline Lugansk & 0.63 & $\underline{0.90}$ & $\underline{1.10}$ & $\underline{1.10}$ & $\underline{0.83}$ & 5.1 & $\underline{6.8}$ & 8.6 & 8.3 & $\underline{6.8}$ \\
\hline Luxembourg & 0.63 & $\underline{0.70}$ & 0.97 & 0.60 & $\underline{0.93}$ & 5.0 & $\underline{5.9}$ & 7.7 & $\underline{4.7}$ & $\underline{7.2}$ \\
\hline Nikolaev & 0.53 & $\overline{1.10}$ & $\overline{0.77}$ & $\overline{0.63}$ & $\overline{0.80}$ & 4.3 & $\overline{8.3}$ & $\underline{6.2}$ & $\overline{4.5}$ & $\overline{6.7}$ \\
\hline Paris & 0.57 & $\underline{0.87}$ & $\underline{0.80}$ & $\overline{0.80}$ & $\overline{0.93}$ & 4.5 & $\overline{6.5}$ & $\overline{6.3}$ & $\overline{6.1}$ & $\underline{\overline{7.3}}$ \\
\hline Salamanca & 0.83 & $\overline{1.03}$ & $\overline{1.03}$ & $\underline{1.10}$ & $\overline{0.93}$ & 6.3 & $\overline{8.3}$ & $\overline{\overline{7.3}}$ & $\overline{8.7}$ & $\underline{\overline{6.9}}$ \\
\hline \multirow[t]{2}{*}{ Sodankyla } & 0.53 & $\overline{0.87}$ & $\overline{0.67}$ & $\overline{0.60}$ & $\overline{0.90}$ & 3.9 & $\overline{6.8}$ & $\overline{5.2}$ & $\overline{4.4}$ & $\underline{\overline{7.3}}$ \\
\hline & \multicolumn{5}{|c|}{ _ HW_D (days) } & \multicolumn{5}{|c|}{ — HW_I (degree-days) } \\
\hline Arad & 4.0 & $\underline{4.3}$ & $\underline{4.5}$ & 4.0 & $\underline{3.7}$ & 9.7 & 11.7 & 11.0 & 10.4 & 10.6 \\
\hline Bordeaux & 1.9 & $\underline{3.3}$ & 4.2 & 3.8 & 4.3 & 6.0 & $\underline{8.2}$ & 9.4 & 8.1 & 8.8 \\
\hline CET & 4.9 & $\underline{3.6}$ & $\underline{3.9}$ & $\underline{4.5}$ & $\underline{3.5}$ & 15.9 & $\underline{11.3}$ & 13.0 & $\underline{14.4}$ & 10.7 \\
\hline Elatma & 4.7 & $\underline{5.6}$ & $\underline{6.1}$ & $\underline{6.8}$ & $\underline{4.5}$ & 13.9 & 16.4 & 15.7 & 19.9 & 12.6 \\
\hline Falun & 4.1 & $\underline{4.8}$ & $\underline{4.5}$ & $\underline{3.8}$ & $\underline{3.7}$ & 10.8 & $\underline{12.4}$ & $\underline{10.1}$ & $\underline{8.0}$ & 9.5 \\
\hline Halle & 4.1 & $\underline{4.1}$ & $\underline{3.6}$ & $\underline{4.8}$ & $\underline{3.9}$ & 11.2 & 11.7 & $\underline{10.3}$ & $\underline{11.8}$ & $\underline{13.0}$ \\
\hline Larissa & 3.5 & $\overline{4.1}$ & $\overline{4.5}$ & $\overline{4.6}$ & $\overline{3.2}$ & 9.7 & $\overline{9.6}$ & $\overline{13.3}$ & $\overline{13.9}$ & $\overline{8.6}$ \\
\hline Lugansk & 4.1 & $\overline{5.1}$ & $\overline{\overline{5.8}}$ & $\underline{\overline{4.9}}$ & $\overline{4.3}$ & 11.7 & $\underline{13.1}$ & $\underline{\overline{17.8}}$ & $\underline{\overline{13.8}}$ & $\underline{14.1}$ \\
\hline Luxembourg & 3.4 & 4.9 & $\underline{5.5}$ & 3.5 & $\underline{4.8}$ & 11.2 & $\underline{10.4}$ & 10.6 & $\underline{8.3}$ & 12.8 \\
\hline Nikolaev & 3.9 & $\underline{5.4}$ & $\underline{3.9}$ & $\underline{2.7}$ & $\underline{4.9}$ & 10.6 & 15.0 & 10.3 & $\overline{6.0}$ & 9.4 \\
\hline Paris & 2.9 & $\overline{3.8}$ & $\overline{4.2}$ & $\overline{3.9}$ & $\overline{4.5}$ & 10.4 & 8.4 & $\overline{9.4}$ & 9.3 & 13.6 \\
\hline Salamanca & 4.6 & $\underline{4.9}$ & $\overline{4.5}$ & $\overline{4.9}$ & 4.6 & 11.6 & $\overline{11.3}$ & 10.7 & $\overline{10.7}$ & 8.9 \\
\hline Sodankyla & 2.8 & $\overline{5.0}$ & $\underline{4.0}$ & $\underline{4.4}$ & $\underline{4.5}$ & 8.5 & 12.6 & $\underline{9.0}$ & $\underline{9.5}$ & $\underline{9.0}$ \\
\hline
\end{tabular}

heat waves across Europe for the present-day climate, with $<2$ heat wave events per year in average over the 1961-1990 period. The $30 \mathrm{yr}$ averages of N_HW, HW_D, HW_F and HW_I annual values from the 4 control run experiments (not shown) are, in accordance with observations at the 13 selected stations, below 1.5, 8 and $12 \mathrm{~d}$ and 18 degree-days across the whole continent, respectively. These results therefore provide a measure of credibility to the model projections of future heat wave occurrences as defined in the present work.

\section{FUTURE CLIMATE (2071-2100)}

The predictions presented in this section deal with the 4 model chains (validated in Section 4) and the 5 predictions of climate change reported in Table 1 (1 B2 and 4 A2 scenarios), which cover the range of uncertainties obtained in the 2071-2100 daily temperature from a total of 20 PRUDENCE experiments (Déqué 2003, Déqué et al. 2007). A summary of all PRUDENCE model projections of changes may be found in Christensen \& Christensen (2007). 


\subsection{Changes in the probability distributions of $t_{\max }$}

\subsubsection{Annual changes}

Fig. 3 presents the temperature change $\left({ }^{\circ} \mathrm{C}\right)$ in the mean, 90th percentile and inter-quartile range (75th 25th $t_{\max }$ percentile), as simulated between past and future climates for the B2 and A2 scenarios. Consistent with previous climate change studies (IPCC 2001), a change in the mean annual temperature between 3 and $5^{\circ} \mathrm{C}$ is obtained across all of Europe from the HadAM3Hdriven A2 experiments, whereas the B2 scenario leads to similar patterns, although with about $1^{\circ} \mathrm{C}$ less change.

The greatest differences between the simulations are linked to the boundary conditions, i.e. to the driving GCM, as revealed by a change of up to $8^{\circ} \mathrm{C}$ in the mean obtained in the case of the ECHAM model. Results for the other statistical distribution parameters, as defined in Section 3 (not shown), reveal that, for a large part of southern Europe, the higher the percentile (perc.) considered, the higher the simulated positive change $\Delta$ (i.e. $\Delta_{99 \text { th perc. }}>\Delta_{95 \text { th perc. }}>\Delta_{90 \text { th perc. }}>$ $\Delta_{75 \text { th perc. }}>\Delta_{\text {mean }}$ and $\left.\Delta_{\text {median }}\right)$. This implies that the change in extreme values of temperature is not only explained by an overall shift in the mean, but also by an additional change in the variability of the distribution. As a matter of fact, the change in the inter-quartile range (Fig. 3b) shows more heterogeneous changes across Europe compared to the change

Fig. 3. Changes in the (a) mean, (b) inter-quartile range $(75$ th 25th percentile) and (c) 90th percentile of the daily maximum temperature $\left({ }^{\circ} \mathrm{C}, \mathrm{N}=2 \times 10800\right.$ daily data), as simulated by 4 GCMRCM model chains for the B2 and A2 emission scenarios. See Table 1 for model definitions in the mean (Fig. 3a): an increase in the inter-quartile range up to $3^{\circ} \mathrm{C}$ is predicted in SW Europe (up to $4^{\circ} \mathrm{C}$ in SW France), whereas a slight negative change is foreseen in the eastern part of Scandinavia and in Central Europe for the HadAM3H-driven experiments. In the case of the ECHAM GCM, the whole northeastern part of Europe shows a decrease in variability, whereas a more pronounced northeast $(-20 \%)$ to southwest $(+50 \%)$ gradient is evident than that obtained with the
B2.3
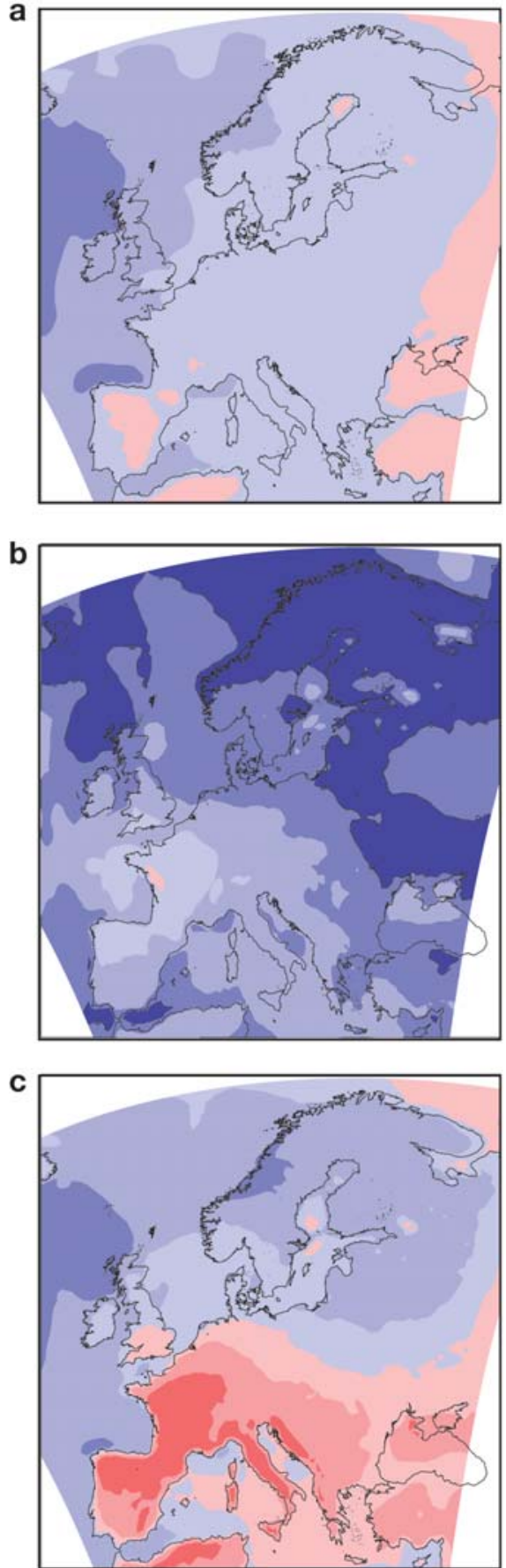

A2.1
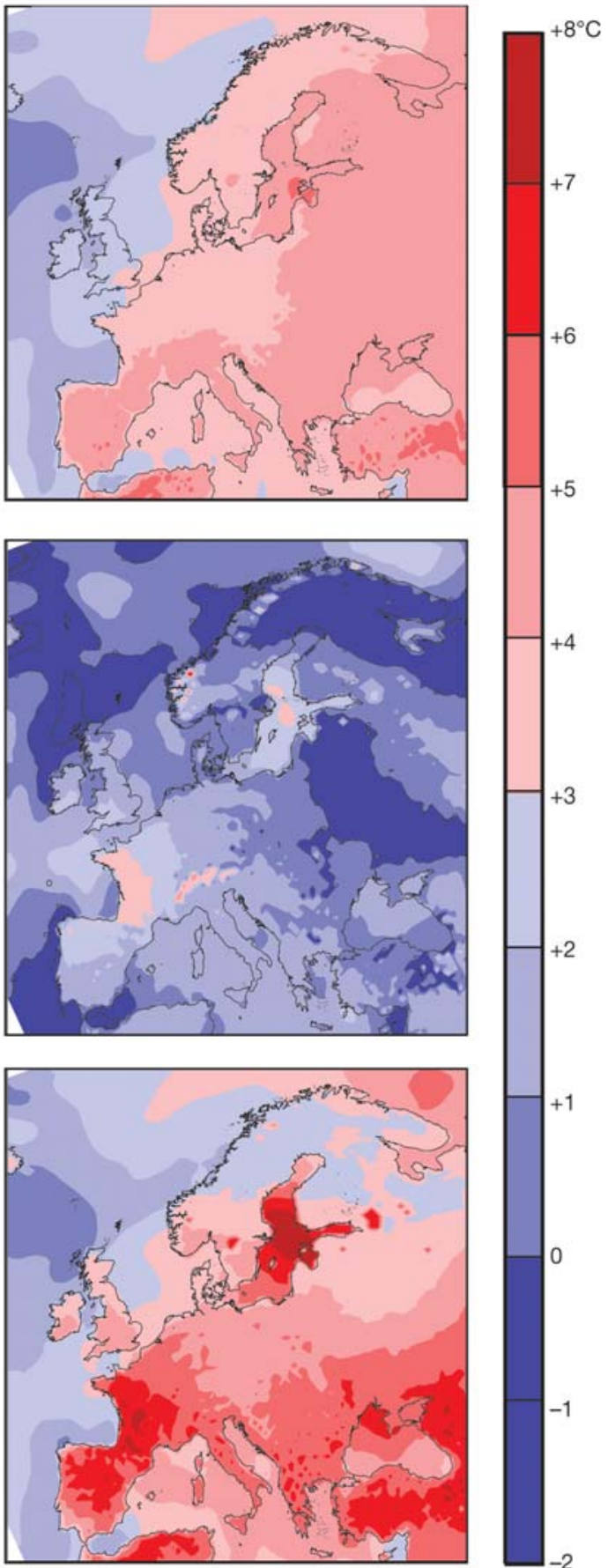
HadAM3H GCM. Negative and positive changes are simulated on either side of a transect from Denmark to the Danube delta. As a result of these changes in temperature variability, all experiments predict the highest and lowest increases in high percentiles across France and Scandinavia, respectively (Fig. 3c). Applying the Levene $F$-test $(\alpha>5 \%)$ on variance showed these changes in $t_{\max }$ variability to be significant over at least $90 \%$ of the domain study (depending on the model).

\subsubsection{Seasonal changes}

The respective contributions of shifts in the location and spread of the distribution to the total change in high percentile values were calculated at a seasonal time scale, following Ferro et al. (2002). The results for the summer months reveal a significant remaining increase in the 99th percentile (e.g. up to $60 \%$ in France and Central Europe) after adjusting for the change in the central
A2.2
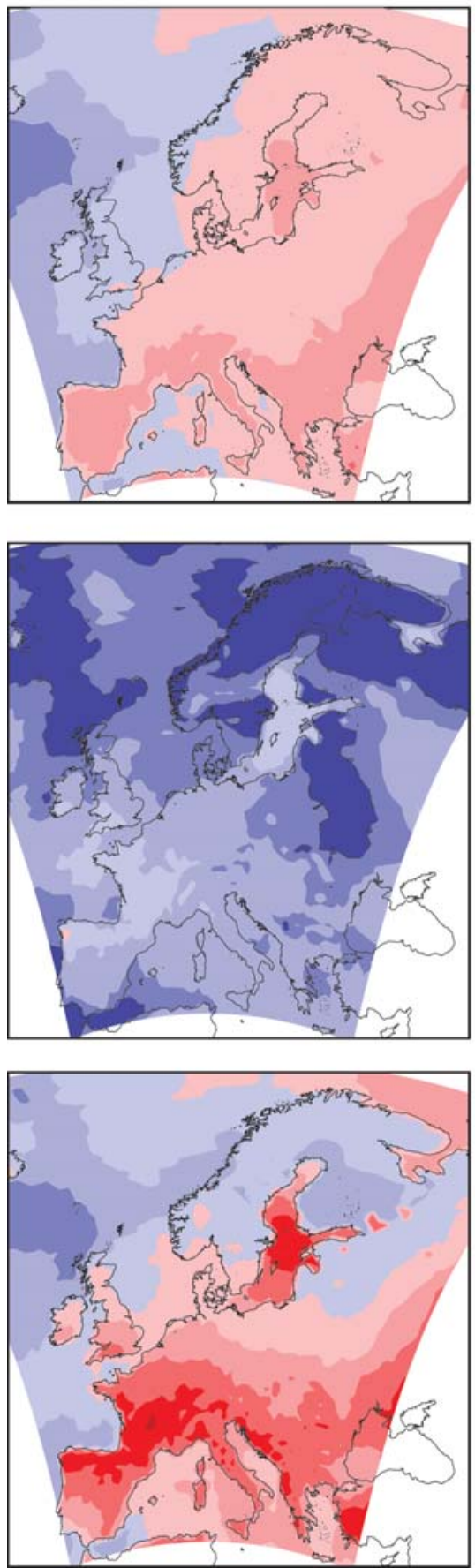

A2.3
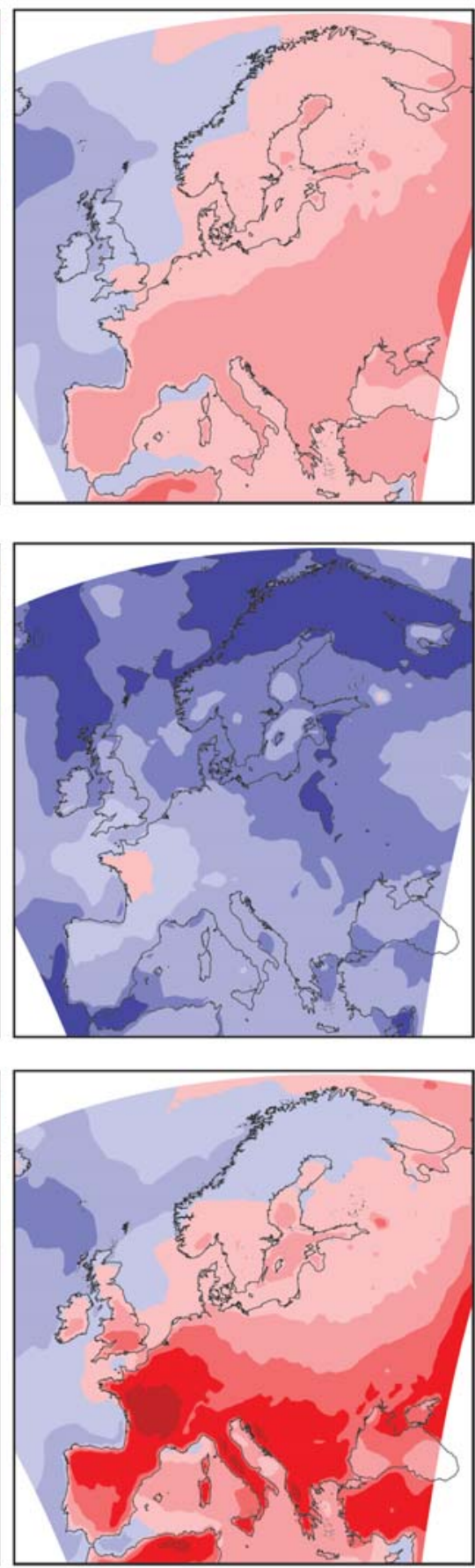

A2.4
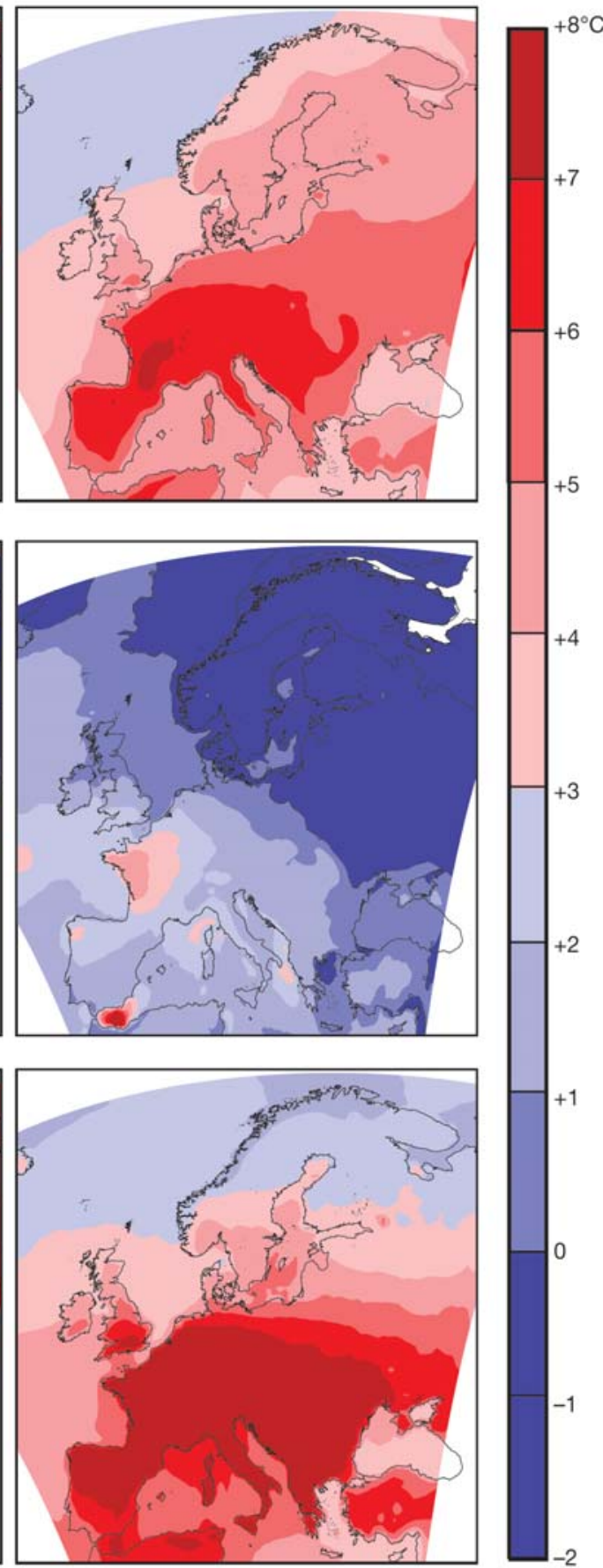

$8^{\circ} \mathrm{C}$ 
position (median) of the PDF. This additional increase was shown in a previous study to be due primarily to a change in variability (Koffi et al. 2003). These results for the summer season are in line with those of other investigations carried out within the framework of PRUDENCE (e.g. Schär et al. 2004), which found large summertime changes in extremely high temperatures in central, eastern and southern Europe, i.e. higher than average temperature increase. Moreover, and in accordance with Kjellström (2004), the present study also reveals that the shapes of the temperature distributions change differently, not only depending on the location but also on the season. Whereas Central Europe experiences a small positive or sometimes even a negative change in the inter-quartile range at an annual time scale (Fig. 3), it shows the most pronounced relative increase in variability for the summer season.

The 3 RCMs when driven by the HadAM3H GCM gave very similar results in the heat wave frequency, intensity and duration indices. Therefore, for the sake of brevity, only results from the B2.3, A2.3 and A2.4 $\mathrm{RCAO}$ experiments are discussed in the following section. An assessment of the level of confidence in the simulated changes, as a function of uncertainties in the boundary conditions and in radiative forcing, was obtained by comparing A2.3/A2.4 and B2.3/A2.3 experiments, respectively.

\subsection{1-2100 heat wave indices}

\subsubsection{Annual patterns}

The 2071-2100 averaged frequency and intensity indices, as simulated by the RCAO model for the A2 scenario and the HadAM3H-driving GCM are presented in Fig. 4. Very similar spatial patterns were simulated for the B2 scenario (not shown). Simulations for the B2/A2 scenarios predict from 20/40 (e.g. northern part of Scandinavia) up to $100 / 150$ heat wave days per year around the Mediterranean Sea and in southern Scandinavia. All the simulations reveal north-south gradients in western Europe and in the Scandinavian countries (Fig. 4a). Similar spatial patterns were obtained for the number of heat waves (not shown) with the highest values (>8) obtained around the Mediterranean Sea. A similar but more pronounced northeast-southwest gradient was also predicted in western Europe for the heat wave intensity index, with an additional area of elevated values in Central Europe (Fig. 4b).

The ratios (not shown) between the 2071-2100 and 1961-1990 periods are as follows:

- The duration index increases by a factor of $2 / 3$ to $9 / 10$ across all of Europe, with the highest changes observed in France, Spain and on the Kola Peninsula (NW Russia).

- A higher increase is predicted for the intensity $(>3 / 4)$ and frequency $(>3 / 5)$ indices.

- In addition to the Mediterranean area and to southern Scandinavia, the RCAO-ECHAM simulations (not shown) also predict maxima of heat wave frequency in the UK and along the Atlantic coast. According to these simulations, half of Europe would experience $>120$ heat wave days per year, with heat waves lasting $>2 \mathrm{mo}$ on average on the southeastern coast of France, in the south of Spain and in the southwest part of England.

The statistical tests described in Section 3 reveal significant changes in heat wave occurrence across the continent, in terms of frequency, duration and intensity, for both A2 and B2 scenarios. Nevertheless, a careful interpretation is required, since they are the sum of the positive and negative effects of the seasonal changes that are discussed in the following subsection.
Fig. 4. The 2071-2100 mean annual heat wave (a) frequency (HW_F, in days) and (b) intensity (HW_I, in degree-days) indices, as simulated by the RCAO regional climate model for the A2 scenario (A2.3 experiment)
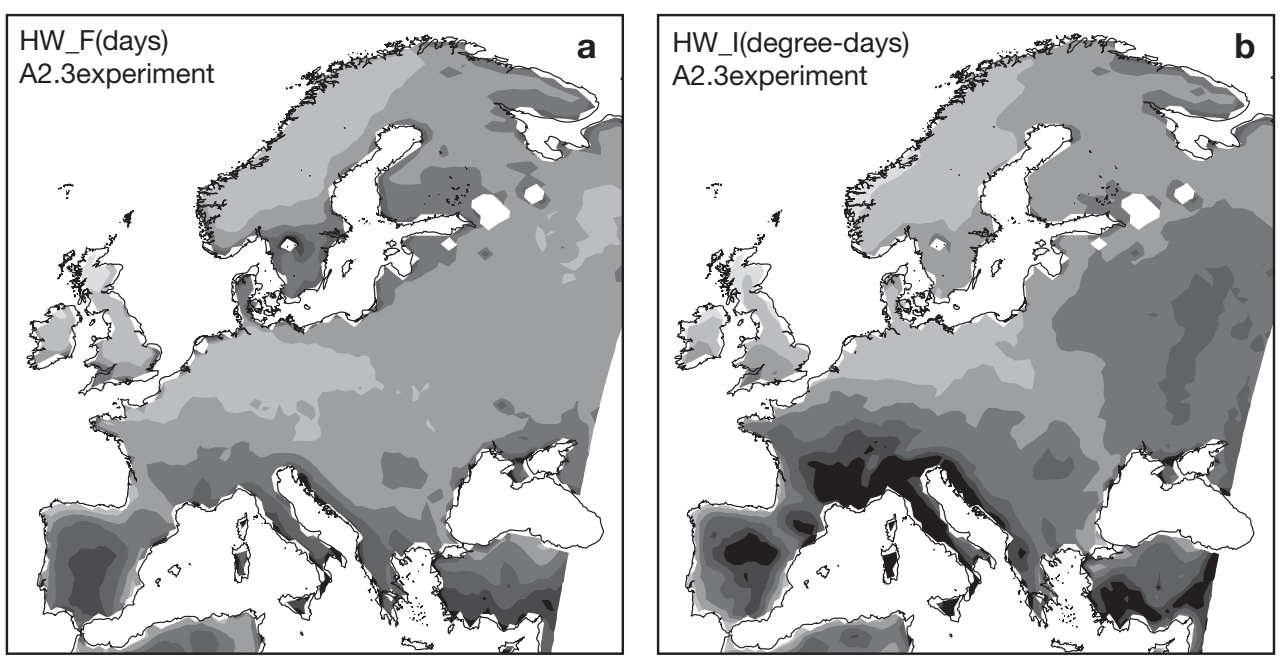


\subsubsection{Seasonal patterns}

Fig. 5 presents the $2071-2100$ seasonal distributions of the HW_F heat wave frequency index (in days) as simulated across Europe by the RCAO regional model for the B2.3 and A2.4 experiments, visualising the range of simulated heat wave occurrences for the future. Results for the other heat wave indices and simulation experiments were also mapped (not shown). The spatial patterns across Europe, which differ according to season, can be summarised as follows:

Summer: the summer season presents the greatest changes in the frequency, duration and intensity heat wave indices, with a strong north-south gradient. The southern half of Europe should experience at least 1 and 2 heat waves per summer on average over the 2071-2100 period for scenarios B2 and A2, respectively (not shown). Up to 50 and 60 heat wave days could locally occur on average during the June to August period, for B2 and A2 scenarios, respectively (e.g. in Spain, Italy, or Greece).

\begin{tabular}{lllllll}
0 & 10 & 20 & 30 & 40 & 50 & 60 \\
\hline
\end{tabular}

Fig. 5. The 2071-2100 mean seasonal heat wave frequency index (HW_F, in days), as simulated across Europe by the RCAO model for the B2 (left panels) and A2 (right panels) scenarios. The corresponding B2.3 and A2.4 experiments, respectively, driven by HadAM3H and ECHAM GCMs, are representative of the range of uncertainties obtained in the 2071-2100 daily maximum temperature from a total of 20 PRU-DENCE experiments
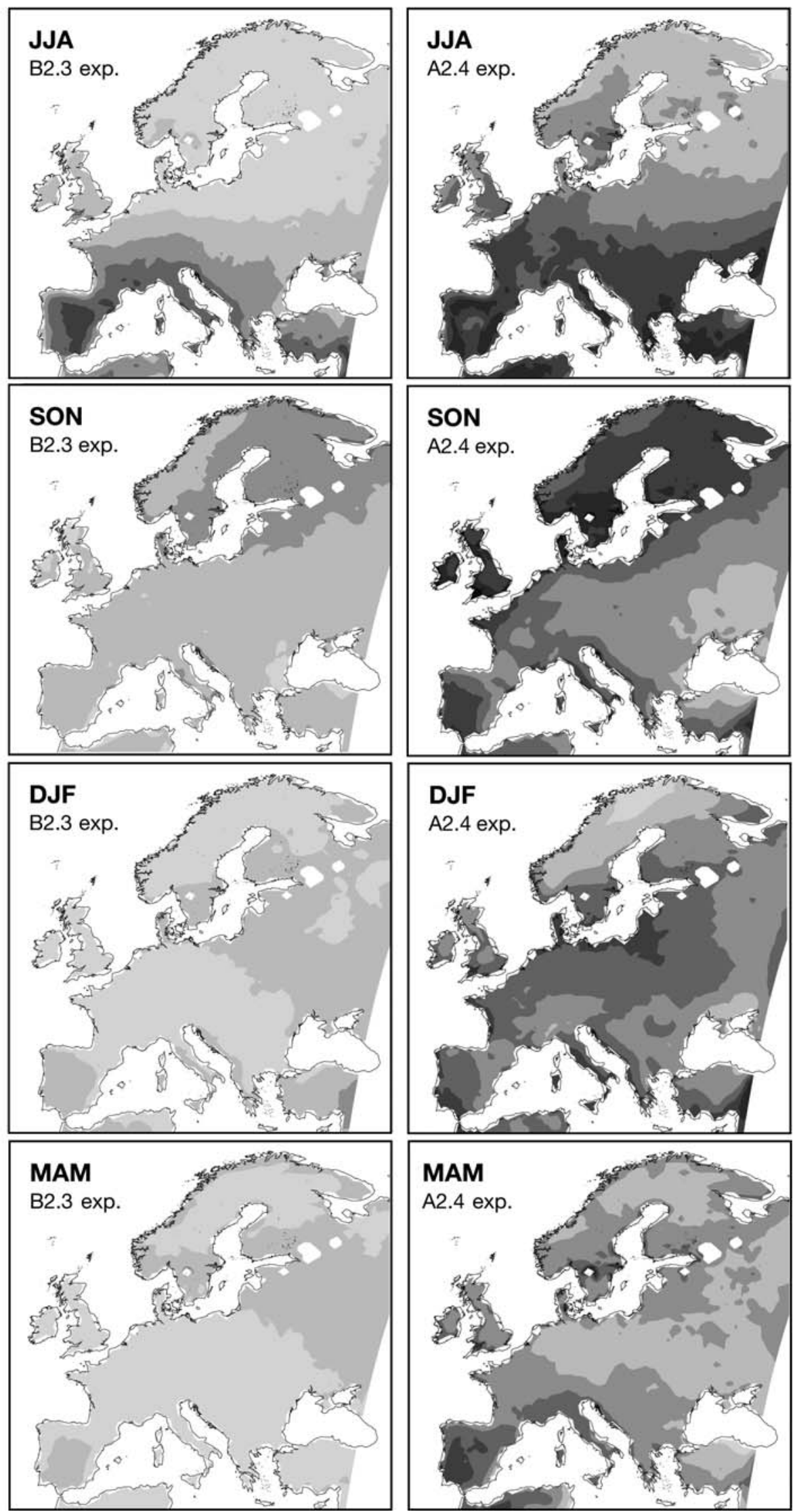
Autumn: this season shows the second highest occurrence of heat waves, but with a very different regional distribution compared to summertime. At least 10 heat wave days per season are predicted across all of Europe. The highest frequency is obtained for Scandinavia. Finland and Sweden show at least $20 \mathrm{~d}$ of heat wave for the B2 scenario, whereas from 30 to 60 heat wave days are predicted across all Scandinavian countries in the case of higher radiative forcing (A2 scenario). According to A2.4 simulations, the British Isles, the northern coast of the European continent, extending from Brittany to Russia, southwestern parts of Spain and Italy and the Adriatic coast would also experience heat wave days during at least one third of the September to November season.

Winter: About one third of Europe would experience at least 10 (or 30) heat wave days on average during winter according to the B2 (or A2) scenario. The main areas of increased heat wave frequency for the winter season are located in Central Europe (around the bays of Gdansk and Riga) and again, around the Mediterranean Sea (southwestern parts of Spain and Italy, and the Adriatic coast).

Spring: This season reveals the least pronounced changes, with the Mediterranean areas experiencing the highest occurrence of heat waves, i.e. above $30 \mathrm{~d}$ across most of Spain and Italy for the A2.1 experiment. The Alps also show elevated increases in the heat wave frequency, duration and intensity indices.

As a local example, the seasonal heat wave indices as simulated at the closest grid point to Paris were calculated. The highest values of 2071-2100 HW_D, HW_F and HW_I indices were simulated for summer and autumn, which present the highest increases in $t_{\text {max }}$ mean and variance values, respectively (cf. Section 5.1). A higher heat wave frequency was obtained for winter than for spring, whereas the opposite was true for intensity. As an illustration of what might happen in the future, results reveal that Paris would experience summertime heat waves as severe as the 2 last record-breaking $1976\left(\mathrm{HW} \_\mathrm{D}=16\right.$ and HW_I = 75) and 2003 (12 and 80, respectively) events, at least once a year on average.

\subsection{Changes with reference to the present-day climate}

Past trends in observed temperature extremes have recently been analysed across Europe within the framework of the ECA project (Frich et al. 2002, Klein Tank \& Können 2003). Results showed a positive trend in the mean temperature from 1976-1999, which was accompanied by higher temperature variance. This led to a significant increase in the heat wave frequency index (HWFI, that corresponds to our HW_F index) of at least 3 d decade ${ }^{-1}$ across most of Europe (Klein Tank et al. 2002), for both the winter half (October to March) and the summer half (April to September) of the year. Fig. 6 shows the simulated trends in days per decade, as calculated across Europe, from the difference between the two $30 \mathrm{yr}$ averaged indices. Results for the B2.3 and A2.4 experiments reveal that the increase from 1976-1999 in the occurrence of heat wave days should continue (winter) or even increase (summer) through to the end of the 21st century. As an illustration of the differing seasonal patterns according to geographical location, the observed (1976-1999) and simulated (1961-2100) trends in the HW_F index are given in Table 3 for Voru (Estonia), Bordeaux (France) and Larissa (Greece) stations. Voru shows a higher increase in the winter half than in the summer half, but the inverse is true for Larissa. In the case of Bordeaux, similar simulated ranges are obtained for both periods.

\section{CONCLUSIONS AND PERSPECTIVES}

Our study showed the ability of the regional climate models in simulating the mean 1961-1990 distribution patterns of the selected heat wave indices. Despite biases in the simulation of the mean and/or extreme absolute temperature values, a statistically significant agreement was obtained, for all the studied stations, between the observed and simulated indices. Using local indices of extremes based on percentile thresholds allows Europe-wide comparison of the same parts of temperature distributions. As a result of the simulated changes in both the mean and the variability of

Table 3. Observed (1976-1999) and simulated (1961-2100) trend coefficients $\left(\mathrm{d}\right.$ decade $^{-1}$ ) of the heat wave frequency index (HW_F) at Voru (Estonia), Bordeaux (France) and Larissa (Greece) stations; see Figs. $1 \& 6$ for locations. Pearson linear regression, 2-tailed, $\alpha<10 \%$

\begin{tabular}{|c|c|c|c|c|}
\hline & \multirow{2}{*}{ Expt } & \multicolumn{3}{|c|}{ Trend in HW_F (d per decade) } \\
\hline & & Voru & Bordeaux & Larissa \\
\hline \multicolumn{5}{|c|}{ Summer half (April-September) } \\
\hline Observed & & +3.8 & +6.2 & +2.5 \\
\hline \multirow[t]{5}{*}{ Simulated } & B2.3 & +1.5 & +2.1 & +2.6 \\
\hline & A2.1 & +2.0 & +4.0 & +6.4 \\
\hline & A2.2 & +2.6 & +4.3 & +4.2 \\
\hline & A2.3 & +2.5 & +3.7 & +6.0 \\
\hline & A 2.4 & +2.8 & +7.4 & +8.1 \\
\hline \multicolumn{5}{|c|}{ Winter half (October-March) } \\
\hline Observed & & +4.1 & +4.5 & +2.8 \\
\hline \multirow{5}{*}{ Simulated } & B2.3 & +3.6 & +1.0 & +1.3 \\
\hline & A2.1 & +4.8 & +2.0 & +3.6 \\
\hline & A 2.2 & +5.1 & +2.3 & +3.1 \\
\hline & A2.3 & +5.6 & +3.1 & +3.1 \\
\hline & A 2.4 & +7.2 & +7.5 & +4.6 \\
\hline
\end{tabular}


Fig. 6. Change (d per decade) in the HW_F index across Europe between the periods 1961-1990 and 2071-2100, as predicted by the RCAO model for the $\mathrm{B} 2$ and A2 scenarios. The corresponding B2.3 and A2.4 future experiments are, respectively, representative of the lowest and within the framework of the PRUDENCE project. Triangles show the locations of the 3 stations for which past and future trends in the HW_F index are given in Table 3 highest changes simulated
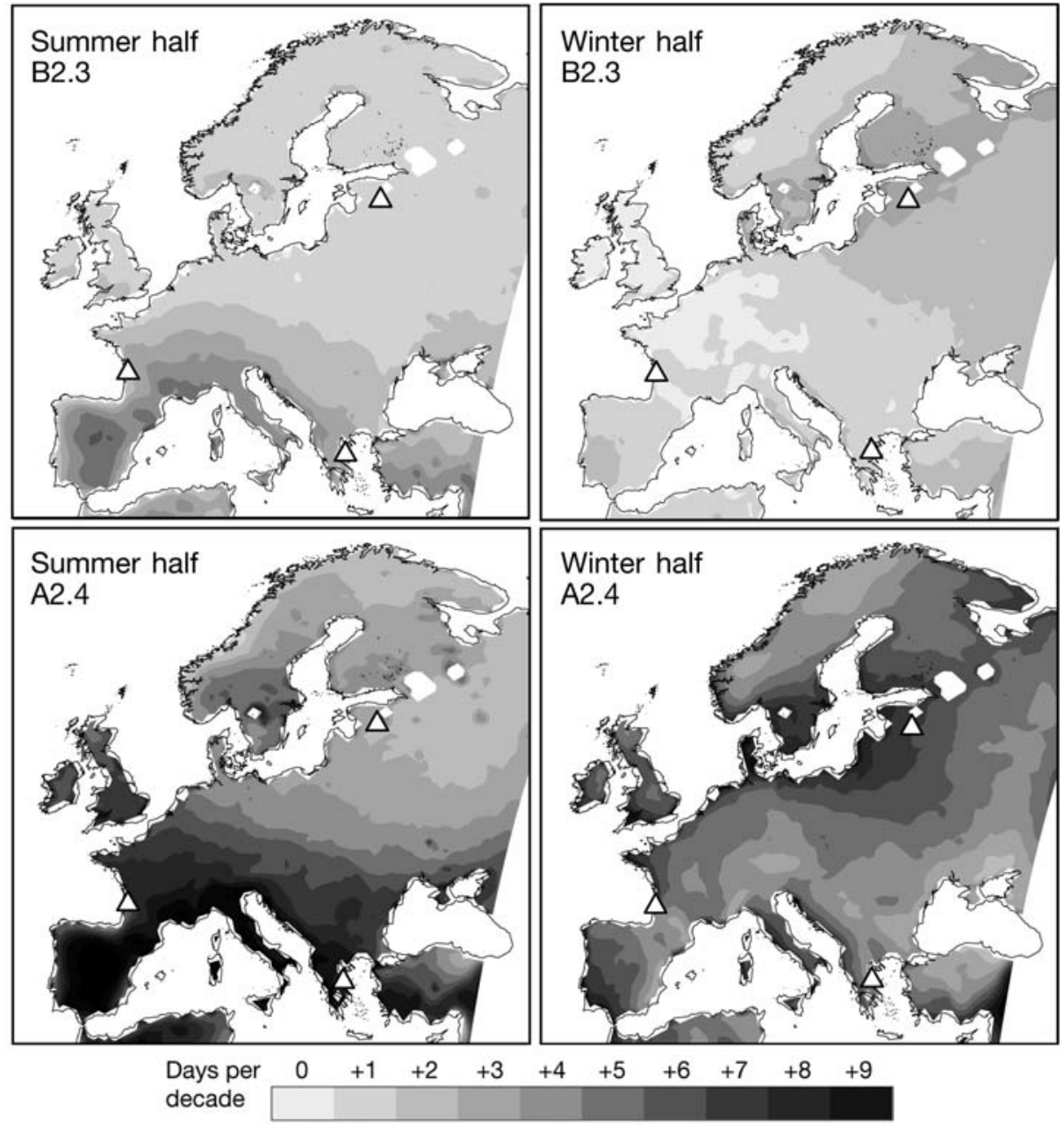

the $t_{\text {max }}$, a statistically significant increase in the heat wave occurrence was obtained across Europe. If the model projections turn out to be realistic, the occurrence of heat waves will become a common phenomenon in Europe by the end of the 21st century, i.e. at least once per season on average. The summer and autumn seasons will experience the most frequent and intense heat wave occurrences across southern and northern Europe, respectively. The highest heat wave occurrence in northern Central Europe will be during winter. Mediterranean areas, such as southwestern parts of Spain and Italy, show the highest future heat wave frequency across seasons. The regional and seasonal differences in the future heat wave occurrence are associated with increases/decreases in temperature variability, depending on the season and the location.

This analysis does not exclude the possibility that the simulated changes in temperature frequency distribution might be partly affected by the physics and dynamics (e.g. soil hydrology, land surface energy balance) of the model under consideration. Although the boundary conditions provided by the GCM are the main source of uncertainty, high-resolution simulations play an important role in resolving the smallscale features, which have a greater dependency on the surface boundary (see for instance Chase et al. 2004, Castro et al. 2005). Thus, if heat wave occurrence as predicted by the RCMs is relatively similar on average across Europe, the spread of the responses locally can be very large. Such differences between the RCM signals have also been reported and discussed within the framework of PRUDENCE by Jacob et al. (2007), who found the spread between the models to be larger for the extreme than for the mean temperature values. A more systematic choice of RCM experiments, together with a variety of emission scenarios and global models is underway within the framework of the ENSEMBLES project (Hewitt \& Griggs 2004). It will lead to further assessment of the uncertainties and the interpretation of the likely physical reasons for differences/similarities between model results.

It is beyond the scope of this paper to analyse the implications of the simulated changes in the occur- 
rence of heat waves on human and environmental systems, which will also highly depend on the vulnerability and opportunity of the different populations and ecosystems for adaptation (e.g. Pielke 1998, Zhang et al. 2001, Changnon 2003, Antle et al. 2004). Nevertheless, the results of the present study provide the basis for a better assessment of their effects. The effects of heat wave events on human health are a result of the combined effects of air temperature, humidity, wind speed and radiation, in addition to non-meteorological components (see e.g. Robinson 2001). But relatively simple indices, such as the heat index (Steadman 1994), which combines temperature and atmospheric moisture, can be used as meteorological measures of heat stress (Kalkstein \& Davis 1989, Gaffen \& Ross 1998, Robinson 2001). Previous modelling studies (e.g. Delworth et al. 1999) showed that changes in the heat index at the global scale are largely determined by changes in the surface air temperature, whereas increases in atmospheric moisture only amplify the changes across present warm and humid climate regions (e.g. the tropics and, during the summer, the extra-tropics). Therefore, the present study, only based on temperature but using higher spatial resolution simulations and site-dependent thresholds constitutes an improvement in evaluation of the European regions that should be the most affected in terms of human health by the predicted future increase in summer heat wave occurrence.

Current work focuses on the development of new indices to better assess the potential impact of heat waves on human health (B. Koffi unpubl.) and on tropospheric ozone pollution. Health risk due to heat waves, e.g. excess mortality, is often correlated to both daytime and nighttime maximum temperatures (see e.g. Basu \& Samet 2002, Vescovi et al. 2005), and largescale heat waves are generally associated with severe photochemical episodes, which enhance their harmful effects (e.g. Beck et al. 1999, Koffi 2002, Stedman 2004).

Acknowledgements. This study was performed at the University of Fribourg (Switzerland) and was supported by the European Union under Contract EVK2-CT-2001-00132. It is part of the PRUDENCE (Prediction of Regional scenarios and Uncertainties for Defining EuropeaN Climate change risks and Effects) project (http://prudence.dmi.dk). We very much thank O. Christensen from the Danish Meteorological Institute for providing access to the climate simulations and for related technical support. We are also very grateful to $M$. Rebetez from the WSL Swiss Federal Institute for allowing us to finalize this paper, to R. A. Robinson for review of the English, and to 4 reviewers for constructive comments. The NCEP-NCAR data were provided by the NOAA-CIRES Climate Diagnostics Center, Boulder, Colorado, USA, from their web site at www.cdc.noaa.gov/. The ECA observation dataset used for the model validation is available from The Royal Netherlands Meteorological Institute (KNMI) at www.knmi.nl/ samenw/eca/.

\section{LITERATURE CITED}

Antle JM, Capalbo SM, Eliott ET, Paustian KH (2004) Adaptation, spatial heterogeneity, and the vulnerability of agricultural systems to climate change and $\mathrm{CO}_{2}$ fertilization: an integrated assessment approach. Clim Change 64: 289-315

Basu R, Samet JM (2002) Relation between elevated ambient temperature and mortality: a review of the epidemiologic evidence. Epidemiol Rev 24:190-202

Beck JP, Krzyzanowski M, Koffi B (1999) Tropospheric ozone in the European Union: the consolidated report. Report to the European Commission, European Environment Agency, Copenhagen

Bell JL, Sloan LC, Snyder MA (2004) Regional changes in extreme climatic events: a future climate scenario. J Clim 17:81-87

Beniston M, Keller F, Koffi B, Goyette S (2003) Estimates of snow accumulation and volume in the Swiss Alps under changing climatic conditions. Theor Appl Climatol 76: 125-140

Beniston M, Stephenson DB, Christensen OB, Ferro C and others (2007) Future extreme events in European climate: an exploration of regional climate model projections. Clim Change 81(Suppl 1):71-95

Brabson BB, Palutikof JP (2002) The evolution of extreme temperatures in the Central England temperature record. Geophys Res Lett 29:2163

Buonomo E, Jones R, Huntingford C, Hannaford J (2007) On the robustness of changes in extreme precipitation simulated by two regional climate models over Europe. Q J R Meteorol Soc 133:65-81

Castro CL, Pielke RA Sr, Leoncini G (2005) Dynamical downscaling: assessment of value retained and added using the regional atmospheric modeling system (RAMS). J Geophys Res 110:D05108

Changnon SA (2003) Shifting economic impacts from weather extremes in the United States: a result of societal changes. Nat Hazards 29:273-290

Chase TN, Pielke RA, Herman B, Zeng X (2004) Likelihood of rapidly increasing surface temperature unaccompanied by strong warming in the free troposphere. Clim Res 25: 185-190

Christensen JH, Christensen OB (2007) A summary of the PRUDENCE model projections of changes in European climate by the end of the century. Clim Change 81 (Suppl 1):7-30

> Christensen OB, Christensen JH, Machenhauer B, Botzet M (1998) Very high resolution regional climate simulations over Scandinavia - present climate. J Clim 11:3204-3229

Christensen JH, Carter RT, Rummukainen M, Amanatidis G (2007) Evaluating the performance and utility of regional climate models: the PRUDENCE project. Clim Change 81(Suppl 1):1-6

Cubasch U, Meehl GA, Boer GJ, Stouffer RJ and others (2001) Projections of future climate change. In: Houghton JT, Ding Y, Griggs DJ, Noguer $M$ and others (eds) Climate change, 2001. Cambridge University Press, Cambridge, p 525-582

DeGaetano AT (1996) Recent trends in maximum and minimum temperature threshold exceedances in the northeastern United States. J Clim 9:1646-1660

$>$ Delworth TL, Mahlan JD, Knutson TR (1999) Changes in heat index associated with $\mathrm{CO}_{2}$-induced global warming. Clim Change 43:369-386

Déqué M (2003) Uncertainties in the temperature and precipitation response of PRUDENCE runs over Europe. Ab- 
stract from the European Science Foundation and PRUDENCE 3rd Ann Conf on Regional Climate Change in Europe, Wengen, Switzerland, Sept 29-Oct 3, 2003

Déqué M, Rowell DP, Lüthi D, Giorgi F and others (2007) An intercomparison of regional climate simulations for Europe: assessing uncertainties in model projections. Clim Change 81(Suppl 1):53-70

Diffenbaugh NS, Pal JS, Trapp RJ, Giorgi F (2005) Fine-scale processes regulate the response of extreme events to global climate change. Proc Natl Acad Sci USA 102: 15774-15778

Domonkos P, Kysely J, Piotrowicz K, Petrovic P, Likso T (2003) Variability of extreme temperature events in SouthCentral Europe during the 20th century and its relationship with large-scale circulation. Int J Climatol 23: 987-1010

Döscher R, Willén U, Jones C, Rutgersson A, Meier HEM, Hansson U, Graham LP (2002) The development of the coupled regional ocean-atmosphere model RCAO. Boreal Environ Res 7:183-192

Ferro CAT, Hannachi A, Stephenson D (2002) WP5-recommended common diagnostics for PRUDENCE: time-slice comparisons of temperature, wind-speed and precipitation. PRUDENCE technical note, Department of Meteorology, University of Reading, Reading

Frich P, Alexander LV, Della-Marta P, Gleason B, Haylock M, Klein Tank AMG, Peterson T (2002) Observed coherent changes in climatic extremes during the second half of the twentieth century. Clim Res 19:193-212

$>$ Gaffen D, Ross R (1998) Increased summertime heat stress in the U.S. Nature 396:529-530

Gawith MJ, Downing TE, Karacostas TS (1999) Heatwaves in a changing climate. In: Downing TE, Olsthoorn AA, Tol RSJ (eds) Climate change and risk. Routledge, London, p 279-307

Giles BD, Balafoutis CJ (1990) The Greek heat waves of 1987 and 1988. Int J Climatol 10:505-517

Giorgi F, Bi X, Pal JS (2004) Mean, interannual variability and trends in a regional climate change experiment over Europe. I. Present-day climate (1961-1990). Clim Dyn 22: $733-756$

Gordon C, Cooper C, Senior CA, Banks H and others (2000) The simulation of SST, sea ice extents and ocean heat transports in a version of the Hadley Centre coupled model without flux adjustements. Clim Dyn 16:147-166

Grize L, Huss A, Thommen O, Schindler C, Braun-Fahrlànder C (2005) Heat wave 2003 and mortality in Switzerland. Swiss Med Wkly 135:200-205

Hewitt CD, Griggs DJ (2004) Ensembles-based predictions of climate changes and their impacts. Eos 85:566

Huth R, Kysely J, Pokorna I (2000) A GCM simulation of heat waves, dry spells, and their relationships to circulation. Clim Change 46:29-60

IPCC (2001) Climate change 2001: the scientific basis. In: Houghton JT, Ding Y, Griggs DJ, Noguer M and others (eds) Contribution of Working Group I to the Third Assessment Report of the Intergovernmental Panel on Climate Change. Cambridge University Press, Cambridge, Appendix I, p 790

Jacob D, Bärring L, Bøssing Christensen O, Hesselbjerg Christensen J and others (2007) An inter-comparison of regional climate models for Europe: model performance in present-day climate. Clim Change 81(Suppl 1):31-52

- Jones PD, Horton EB, Folland CK, Hulme M, Parker DE, Basnett TA (1999) The use of indices to identify changes in climatic extremes. Clim Change 42:131-149

Jones R, Murphy J, Hassel D, Taylor R (2001) Ensemble mean change in a simulation of the European climate 2071-2100 using the new Hadley Centre regional modelling system HadAM3H/HadRM3H. Hadley Center report, Exeter

Kalkstein LS, Davis RE (1989) Weather and human mortality: an evaluation of demographic and inter-regional responses in the U.S. Ann Assoc Am Geogr 79:44-64

Kalkstein LS, Smoyer KE (1993) The impact of climate change on human health: some international implications. Experientia 49:969-979

Kalnay E, Kanamitsu M, Kistler R, Collins W and others (1996) The NCEP-NCAR 40-year reanalysis project. Bull Am Meteorol Soc 77:437-472

$>$ Kharin VV, Zwiers FW (2000) Changes in the extremes in an ensemble of transient climate simulations with a coupled atmosphere-ocean GCM. J Clim 13:3760-3788

Kjellström E (2004) Recent and future signatures of climate change in Europe. Ambio 33:193-198

Klein Tank AMG, Können GP (2003) Trends in indices of daily temperature and precipitation extremes in Europe, 1946-99. J Clim 16:3665-3680

Klein Tank AMG, Wijngaard JB, Können GP, Böhm R and others (2002) Daily dataset of 20th-century surface air temperature and precipitation series for the European Climate Assessment. Int J Climatol 22:1441-1453

Koffi B (2002) Que sait-on de la pollution photochimique urbaine? Primequal-predit 1995-2000. Connaître pour agir sur la pollution à l'échelle locale. Collection du Predit 'Transports rechercher Innovation', La documentation Française, Paris

Koffi B (2003) Heat waves in Europe under climate change. Abstract from the European Science Foundation and PRUDENCE 3rd Ann Conf on Regional Climate Change in Europe, Wengen, Switzerland, Sept 29-Oct 3, 2003

Koffi B, Goyette S, Beniston M (2003) Assessment of changes in the occurrence of heat waves and wind storms. Geophys Res Abs 5:02655

Kovats S, Wolf T, Menne B (2004) Heatwave of August 2003 in Europe: provisional estimates of the impact on mortality. Eurosurveillance Weekly 3:11

Kysely J (2002) Temporal fluctuation in heat waves at PragueKlementinum, the Czech Republic, from 1901-97 and their relationships to atmospheric circulation. Int J Climatol 22:33-50

Lenderink G, van den Hurk B, van Meijgaard E, van Ulden A (2004) Impact of model physics and boundary relaxation on the summertime interannual variability in RCM simulations. In: Bärring L, Laprise R (eds) Proc Regionalscale Climate Modelling Workshop. High-resolution climate modelling: assessment, added value and applications. WCRP, Lund University, Lund

Lüthi D, Cress A, Davies HC, Frei C, Schär C (1996) Interannual variability and regional climate simulations. Theor Appl Climatol 53:185-209

Mearns LO, Katz RW, Schneider SH (1984) Extreme hightemperature events: changes in their probabilities with changes in mean temperature. J Clim Appl Meteorol 23: 1601-1613

Meehl GA, Zwiers F, Evans J, Knutson T, Mearns L, Whetton P (2000) Trends in extreme weather and climate events: issues related to modelling extremes in projections of future climate change. Bull Am Meteorol Soc 81:427-436

Moberg A, Jones PD (2004) Regional climate model simulations of daily maximum and minimum near-surface temperature across Europe compared with observed station data 1961-1990. Clim Dyn 23:695-715

Nakićenović N, Alcamo J, Davis G, de Vries B and others (2000) Emission scenarios. A special report of Working 
Group III of the Intergovernmental Panel on Climate Change. Cambridge University Press, Cambridge

New M, Hulme M, Jones P (1999) Representing twentiethcentury space-time climate variability. Part I: development of a 1961-90 mean monthly terrestrial climatology. J Clim 12:829-856

Pal JS, Giorgi F, Bi X (2004) Consistency of recent European summer precipitation trends and extremes with future regional climate projections. Geophys Res Lett 31:L13202

Peterson TC, Folland C, Gruza G, Hogg W, Mokssit A, Plummer N (2001) Report on the activities of the Working Group on Climate Change Detection and related Rapporteurs, 1998-2001. Report WCDMP-47, WMO-TD 1071, WMO Geneva

Pielke R Jr (1998) Extreme weather and their societal impacts: What are the facts? In: Schuepp P, Smith P (eds) $\mathrm{C}_{2} \mathrm{GCR}$ Public Symposium 'Extreme weather: Is it increasing?', 27 February 1998, Talk summary 2. C ${ }^{2}$ GCR Quarterly 98(2):5-8

Plummer N, Salinger MJ, Nicholls N, Suppiah R and others (1999) Changes in climate extremes over the Australian region and New Zealand during the twentieth century. Clim Change 42:183-202

Räisänen J, Hansson U, Ullerstig A, Döscher R and others (2003) GCM driven simulations of recent and future climate with the Rossby Centre coupled atmosphere-Baltic Sea regional climate model RCAO. SMHI Rep Meteorol Climatol 101, SMHI, Norrköping

Räisänen J, Hansson U, Ullerstig A, Döscher R and others (2004) European climate in the late 21st century: regional simulations with two driving global models and two forcing scenarios. Clim Dyn 22:13-31

Robinson PJ (2001) On the definition of a heat wave. J Appl Meteorol 40:762-775

Roeckner E, Bengtsson L, Feichter J, Lelieveld J, Rodhe H (1999) Transient climate change simulations with a cou-

Editorial responsibility: Helmut Mayer, Freiburg, Germany pled atmosphere-ocean GCM including the tropospheric sulfur cycle. J Clim 12:3004-3032

Schär C, Vidale PL, Lüthi D, Frei C, Häberli C, Liniger M, Appenzeller C (2004) The role of increasing temperature variability in European summer heatwaves. Nature 427:332-336

Steadman RG (1994) Norms of apparent temperature in Australia. Aust Met Mag 43:1-16

Stedman JR (2004) The predicted number of air pollution related deaths in the UK during the August 2003 heatwave. Atmos Environ 38:1087-1090

Subak S, Palutikof JP, Agnew MD, Watson SJ and others (2000) The impact of the anomalous weather of 1995 on the UK economy. Clim Change 44:1-26

Vescovi L, Rebetez M, Rong F (2005) Assessing public health risk due to extremely high temperature events: climate and social parameters. Clim Res 30:71-78

> Vidale PL, Lüthi D, Frei C, Seneviratne S, Schär C (2003) Predictability and uncertainty in a regional climate model. J Geophys Res 108:D18

WHO (2003) Heatwaves: impacts and response. In: Information note for the 9th meeting of the European Environment and Health Committee of the World Health Organization. WHO, Geneva

Wijngaard JB, Klein Tank AMG, Können GP (2003) Homogeneity of 20th century European daily temperature and precipitation series. Int J Climatol 23:679-692

WMO (1999) Meeting of the Joint CCI/CLIVAR task group on climate indices. World Climate Data and Monitoring Programme, WCDMP No. 37, WMO-TD No. 930, WMO, Bracknell

> Zhang X, Hogg WD, Bonsal BR (2001) A cautionary note on the use of seasonally varying thresholds to assess temperature extremes. Comments on 'The use of indices to identify changes in climatic extremes'. Clim Change 50: 505-507

Submitted: September 11, 2006; Accepted: January 8, 2008 Proofs received from author(s): March 21, 2008 